\title{
Bacillus anthracis Edema Toxin Inhibits Efferocytosis in Human Macrophages and Alters Efferocytic Receptor Signaling
}

\author{
Zijian Pan ${ }^{1, \dagger}{ }^{\text {, Eric K. Dumas }}{ }^{1,2,+}$, Christina Lawrence ${ }^{1}$, Lance Pate ${ }^{1}$, Sherri Longobardi ${ }^{1}$, \\ Xiaodong Wang ${ }^{3}$, Judith A. James ${ }^{1,4}\left(\mathbb{D}\right.$, Susan Kovats ${ }^{1,2} \mathbb{D}$ and A. Darise Farris ${ }^{1,2, *}$ \\ 1 Arthritis and Clinical Immunology Program, Oklahoma Medical Research Foundation, \\ Oklahoma City, OK 73104, USA; zijian-pan@omrf.org (Z.P.); eric_dumas@hms.harvard.edu (E.K.D.); \\ christina-lawrence@omrf.org (C.L.); lcpate86@att.net (L.P.); sherri-longobardi@omrf.org (S.L.); \\ judith-james@omrf.org (J.A.J.); susan-kovats@omrf.org (S.K.) \\ 2 Department of Microbiology and Immunology, University of Oklahoma Health Sciences Center, \\ Oklahoma City, OK 73104, USA \\ 3 Center for Integrative Chemical Biology and Drug Discovery, Division of Chemical Biology and Medicinal \\ Chemistry, Eshelman School of Pharmacy, University of North Carolina at Chapel Hill, \\ Chapel Hill, NC 27599, USA; xiaodonw@unc.edu \\ 4 Departments of Medicine and Pathology, University of Oklahoma Health Sciences Center, \\ Oklahoma City, OK 73104, USA \\ * Correspondence: darise-farris@omrf.org; Tel.: +1-405-271-7389; Fax: +1-405-271-4110 \\ + These authors contributed equally to this work.
}

Received: 19 February 2019; Accepted: 4 March 2019; Published: 7 March 2019

\begin{abstract}
The Bacillus anthracis Edema Toxin (ET), composed of a Protective Antigen (PA) and the Edema Factor (EF), is a cellular adenylate cyclase that alters host responses by elevating cyclic adenosine monophosphate (cAMP) to supraphysiologic levels. However, the role of ET in systemic anthrax is unclear. Efferocytosis is a cAMP-sensitive, anti-inflammatory process of apoptotic cell engulfment, the inhibition of which may promote sepsis in systemic anthrax. Here, we tested the hypothesis that ET inhibits efferocytosis by primary human macrophages and evaluated the mechanisms of altered efferocytic signaling. ET, but not PA or EF alone, inhibited the efferocytosis of early apoptotic neutrophils (PMN) by primary human M2 macrophages (polarized with IL-4, IL-10, and/or dexamethasone) at concentrations relevant to those encountered in systemic infection. ET inhibited Protein S- and MFGE8-dependent efferocytosis initiated by signaling through MerTK and $\alpha \mathrm{V} \beta 5$ receptors, respectively. ET inhibited Rac1 activation as well as the phosphorylation of Rac1 and key activating sites of calcium calmodulin-dependent kinases CamK $1 \alpha$, CamK4, and vasodilator-stimulated phosphoprotein, that were induced by the exposure of M2(Dex) macrophages to Protein S-opsonized apoptotic PMN. These results show that ET impairs macrophage efferocytosis and alters efferocytic receptor signaling.
\end{abstract}

Keywords: Bacillus anthracis; Edema Toxin; macrophage; efferocytosis

\section{Introduction}

Humans acquire anthrax by exposure to Bacillus anthracis spores through cutaneous, gastrointestinal, inhalational, or blood-borne routes. High levels of circulating bacteria occur in systemic anthrax [1]. Baboons infused intravenously with vegetative $B$. anthracis bacilli mimic the systemic disease as exhibited by key features of sepsis [2,3], a life threatening, dysregulated immune response to infection that results in organ failure and often leads to death. Bacterial sepsis 
is associated with high levels of lymphocyte apoptosis [4,5] and increased levels of circulating nucleosomes [6,7] that may arise from uncleared apoptotic cells that have become secondarily necrotic [8]. Nucleosomes contribute to acute septic pathology by promoting intra-alveolar hemorrhage, macro- and microvascular thrombosis, and organ dysfunction [9].

Lymphoid organ macrophages are responsible for the clearance of sudden increases in apoptotic cells by a process known as efferocytosis $[10,11]$. The inhibition of efferocytosis in macrophages may exacerbate sepsis by increasing the burden of sepsis-promoting histones and other damage-associated molecular patterns secondary to defective apoptotic cell clearance. Efferocytosis has been reported to be inhibited by elevated cellular cAMP [12] and requires the binding of macrophages to apoptotic cells followed by macrophage signaling events that lead to Rac1-dependent apoptotic cell engulfment [13-15]. Direct binding is mediated by tethering receptors, while indirect binding occurs via soluble proteins that bridge the binding of apoptotic cells to macrophages. There are approximately 12 known signaling receptors that can be divided into (i) those that require bridge proteins to bind apoptotic cells and (ii) those that do not [13]. Among the former, which were evaluated in this study, Tyro3, Axl, and MerTK (TAM family) require the bridge proteins Gas6 or Protein S [16], while $\alpha$ V $\beta 3$ and $\alpha \mathrm{V} \beta 5$ require MFGE8 $[17,18]$ or CCN1 [19]. Efferocytic macrophages in secondary lymphoid organs express MerTK [10] and alternative/M2-like markers CD163 and CD206 [20]. Glucocorticoids such as dexamethasone (Dex), which have been historically used to treat severe sepsis [21,22], enhance macrophage efferocytosis by increasing the expression of the efferocytosis receptor MerTK and its cofactors Protein S and Gas6 [23,24].

In addition to its poly-D-glutamic acid capsule, the major known B. anthracis virulence factors include Lethal Toxin (LT) and Edema Toxin (ET), formed by the association of the cell-binding protein Protective Antigen (PA) with the active components Lethal Factor (LF) or Edema Factor (EF), respectively $[25,26]$. PA binds to at least two independent receptors on the target cells $[27,28]$, undergoes cleavage and multimerization on the cell surface, and then facilitates the binding and translocation of the LF/EF moieties into the cytosol, where they exert their toxic activities. EF is a calcium- and calmodulin-dependent adenylate cyclase that increases intracellular cAMP concentrations to supraphysiologic levels [29]. Mechanisms of ET-induced virulence and tissue damage during infection are not fully understood but may involve the inhibition of innate immunity during early stage infection and direct effects on liver tissue [26]. ET has numerous effects on immune cells, such as the inhibition of macrophage chemotaxis [30] and phagocytosis [31], the rescue of macrophages from Toll-like receptor 4-induced apoptosis [32], the inhibition of neutrophil priming and motility [33-35], the alteration of dendritic cell cytokine secretion, maturation and chemotaxis [36-38], the suppression of $\mathrm{T}$ cell activation and chemotaxis $[30,39,40]$, and the skewing of $\mathrm{CD}^{+} \mathrm{T}$ cell differentiation to the Th2 subset [41].

As efferocytosis is sensitive to cAMP [12], this study tested the hypothesis that ET inhibits efferocytosis initiated by MerTK and integrin $\alpha \mathrm{V} \beta 5$ signaling pathways and explored the intracellular signaling events impacted. The results demonstrate that ET inhibits macrophage-mediated efferocytosis, Rac1 signaling, and the phosphorylation of $\mathrm{Ca}^{2+} /$ calmodulin-dependent protein kinases, Rac1 and vasodilator-stimulated phosphoprotein (VASP) induced by apoptotic cell exposure.

\section{Results}

\subsection{Bacillus anthracis Edema Toxin (ET) Inhibits Efferocytosis in a Dose-Dependent Manner}

Macrophages in secondary lymphoid organs are likely to be important for clearing apoptotic lymphocytes in sepsis and for expressing M2-associated markers CD163 and CD206 [20]. As M2 polarizing stimuli are known to promote pro-efferocytic macrophage phenotypes $[23,24,42]$ and the expression of CD163 and CD206 [43,44], we assessed whether ET could inhibit efferocytosis by human macrophages polarized with a combination of the M2 stimuli IL-4, IL-10, and dexamethasone. M2(IL-4+IL-10+Dex) macrophages expressed high levels of CD206 and CD163 but did not upregulate 
CD80, a marker characteristic of classically activated/M1-like macrophages [45] (Figure 1A). In a representative experiment, $30 \%$ of the $\mathrm{CD}_{163}{ }^{+}$M2(IL-4+IL-10+Dex) macrophages had engulfed eFluor670-labeled apoptotic PMN after $2 \mathrm{~h}$ of coculture, whereas pretreatment of the macrophages with ET for $4 \mathrm{~h}$ substantially impaired efferocytosis (Figure 1B). The pretreatment of M2(IL-4+IL-10+Dex) macrophages with various concentrations of ET resulted in the dose-dependent inhibition of efferocytosis, with a calculated $50 \%$ effective concentration $\left(\mathrm{EC}_{50}\right)$ of $0.6 \mathrm{nM}$ (Figure 2).
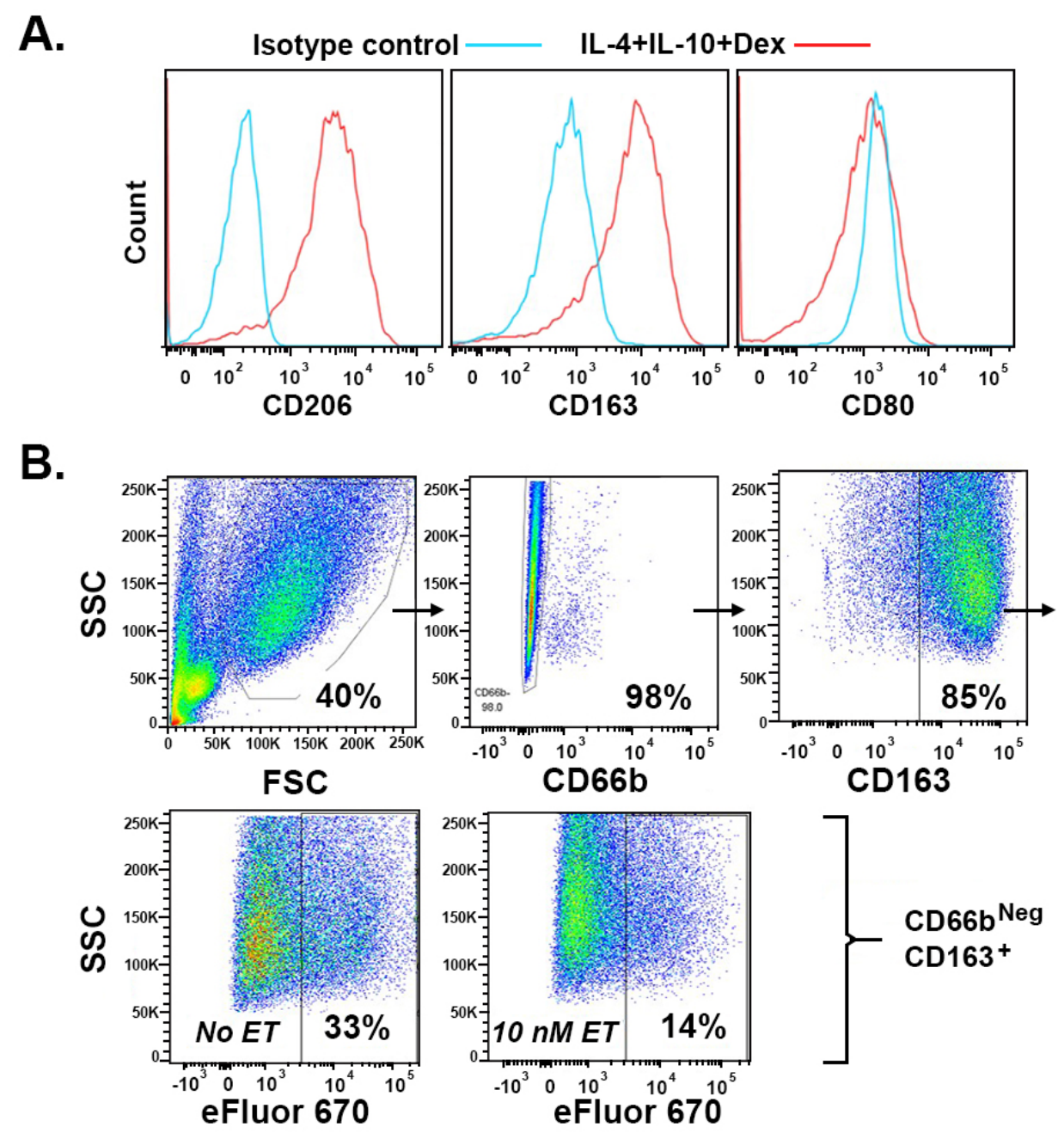

Figure 1. M2(IL-4+IL-10+Dex) macrophages express M2 markers and are more efferocytic in the absence of ET. (A) M2(IL-4+IL-10+Dex) macrophages express CD206 and CD163 but not CD80; (B) The representative gating of efferocytic M2(IL-4+IL-10+Dex) macrophages that were pretreated in the absence (No ET) or presence (10 nM ET) of ET: After excluding un-engulfed apoptotic polymorphonuclear neutrophil (PMN) (FSC vs. SSC, upper left) and macrophages that have surface bound apoptotic PMN detected with the PMN-specific marker CD66b (upper center), the M2 macrophages were selected by positivity for CD163 (upper right). The efferocytic cells were identified as $\mathrm{CD}_{163}{ }^{+} \mathrm{CD} 66 \mathrm{~b}^{-}$macrophages that had internalized eFluor670-labeled apoptotic PMN. The data are representative of five independent experiments showing similar results. 
A.

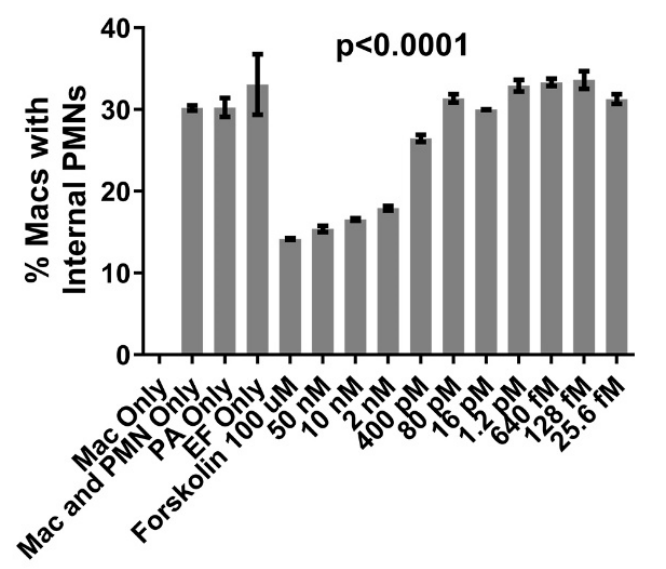

B.

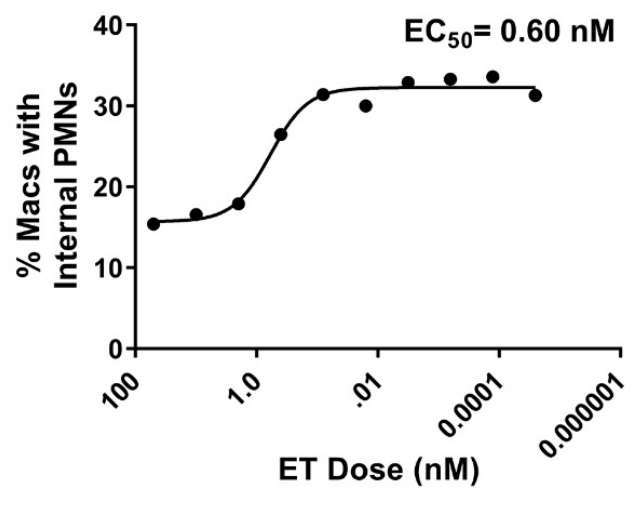

Figure 2. ET inhibits efferocytosis by M2(IL-4+IL-10+Dex) macrophages at a $50 \%$ effective concentration $\left(\mathrm{EC}_{50}\right)$ of $0.6 \mathrm{nM}$ : (A) The inhibition of efferocytosis of apoptotic PMNs by various doses of ET. The controls included macrophages without added apoptotic PMN or ET (Mac Only), macrophages and apoptotic PMN without ET components (Mac and PMN Only), macrophages and apoptotic PMN with PA but without EF (PA Only), macrophages and apoptotic PMN with EF but without PA (EF Only), and an alternative stimulus for the induction of cAMP (Forskolin $100 \mu \mathrm{M}$ ). The data were analyzed by one-way ANOVA compared to wells lacking ET; (B) The calculated EC $_{50}$ of the efferocytosis inhibition using log-transformed ET dose and four-parameter nonlinear regression.

2.2. Efferocytosis by Monocyte-Derived Macrophages Polarized by Dexamethasone (Dex) Depends on Protein S in the Absence of Serum

Dexamethasone (Dex) alone has been shown to enhance macrophage efferocytosis by a Protein Sand MerTK-dependent mechanism [23], as well as to increase the macrophage expression of CD163 [44] and CD206 [43]. To create a more defined system to assess the effect of ET on MerTK-dependent efferocytosis, we first sought to confirm that Dex consistently induces these phenotypes in human monocyte-derived macrophages by evaluating its effect on human macrophage cell surface markers and efferocytic function using flow cytometry. As expected, macrophages polarized overnight by Dex (M2(Dex) macrophages) expressed increased levels of M2-related surface markers CD206 and CD163 (Figure 3A) and were highly efferocytic, with over $60 \%$ of macrophages engulfing the labeled apoptotic PMN after $1 \mathrm{~h}$ of coculture (Figure 3B). The M2(Dex) macrophages expressed elevated surface levels of MerTK compared to the macrophages incubated overnight in the absence of Dex (Figure 3C). In contrast, the expression of Tyro3 or Axl TAM family members were not upregulated on the M2(Dex) macrophages (Figure 3C).

To establish the involvement of MerTK in efferocytosis by M2(Dex) macrophages in our hands, the polarized cells were pretreated with various concentrations of a selective MerTK inhibitor (UNC1062A) [46] for $1 \mathrm{~h}$ prior to coculture with apoptotic human PMN and to the assessment of efferocytosis by flow cytometry. UNC1062A suppressed efferocytosis by human M2(Dex) macrophages in a dose-dependent manner (Figure 4A), indicating that efferocytosis by these macrophages is dependent on MerTK in our system. Moreover, UNC1062A did not induce intracellular cAMP in M2(Dex) macrophages (Figure S1A), supporting its specific effect on MerTK signaling. To determine if ET inhibits efferocytosis initiated by MerTK signaling, human M2(Dex) cells were preincubated with $10 \mathrm{nM} \mathrm{EF}, 10 \mathrm{nM}$ PA, or ET (10 nM PA + $10 \mathrm{nM} \mathrm{EF)} \mathrm{or} \mathrm{left} \mathrm{untreated} \mathrm{for} 4 \mathrm{~h}$. MerTK-dependent efferocytosis was assessed by measuring the engulfment of Protein S-opsonized human PMN in the absence of serum by flow cytometry. The opsonization of apoptotic PMN with both serum and Protein $S$ enhanced efferocytosis by M2(Dex) macrophages (Figure 4B). Furthermore, ET, but not PA or EF alone, inhibited Protein S-enhanced efferocytosis by M2(Dex) macrophages (Figure 4B). The evaluation 
of intracellular cAMP in M2(Dex) macrophages treated with EF, PA, or ET confirmed the upregulation of cAMP by ET (Figure S1B).

A.

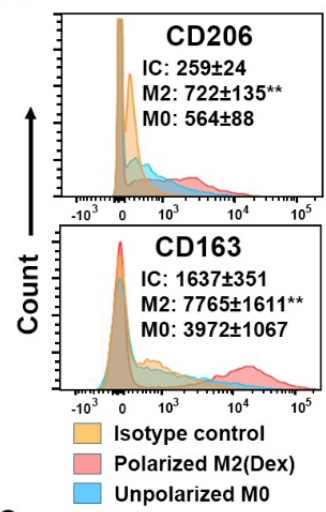

B.

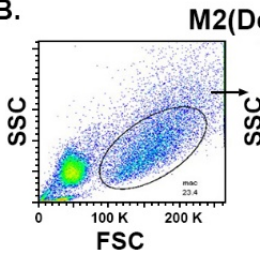

M2(Dex) + apoptotic PMN isotype control
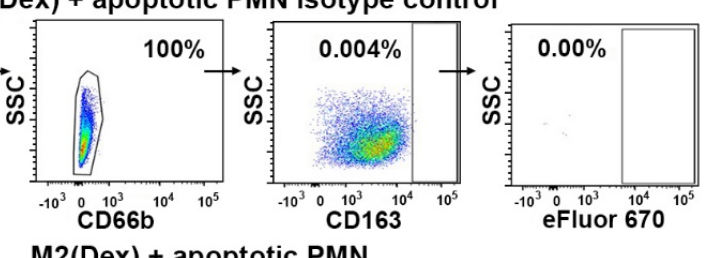

\section{M2(Dex) + apoptotic PMN}
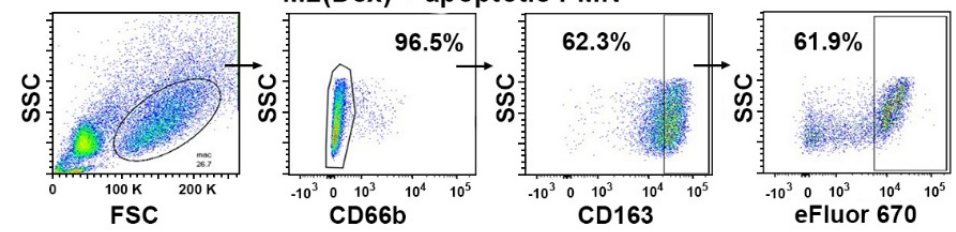

C.
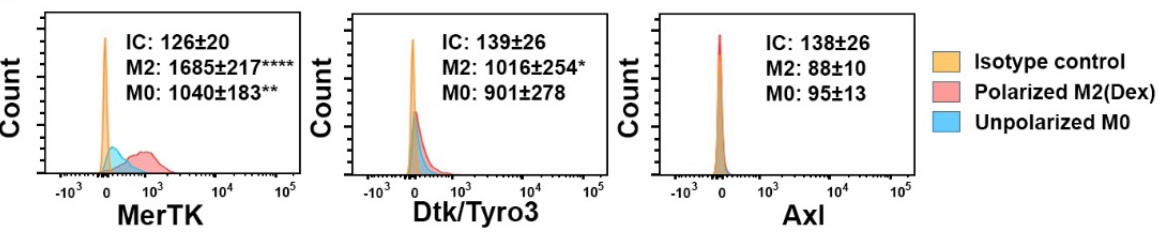

Figure 3. Monocyte-derived macrophages polarized by dexamethasone (M2(Dex) macrophages) expressed M2 markers and were highly efferocytic. (A) The histogram overlays showing the cell surface expression of CD206 and CD163 surface markers on M2(Dex) macrophages (red, M2), unpolarized M0 macrophages (blue, M0), or isotype control antibodies binding to M2(Dex) macrophages (light orange, IC). The mean fluorescence intensities (MFI) \pm SEM of 10 independent donors are indicated; (B) The gating of efferocytosis by M2(Dex) macrophages shows (left to right) the successive exclusion of un-engulfed apoptotic PMN (FSC vs. SSC gate), the exclusion of macrophage cell surface bound $\mathrm{CD}_{6} \mathrm{~b}^{+} \mathrm{PMN}$, the inclusion of $\mathrm{CD} 163^{+} \mathrm{M} 2$ (Dex) macrophages, and the percentage of $\mathrm{CD} 163^{+} \mathrm{CD} 66 \mathrm{~b}^{-}$ macrophages containing engulfed eFluor670 $0^{+} \mathrm{PMN}$. The lower panels show efferocytosis gating. The upper panels depict the staining of cells from the same experiment with the isotype control antibodies for CD66b and CD163; (C) M2(Dex) macrophages express MerTK and Tyro3 but not Axl TAM family members. MFI \pm SEM of 10 independent donors are indicated. ${ }^{*} p<0.05,{ }^{* *} p<0.01$, and ${ }^{* * * *} p<0.0001$ by one-way ANOVA with Tukey's multiple comparison posttest compared to IC.

2.3. MFGE8-Enhanced Efferocytosis by Human M2(Dex) Macrophages Is Associated with Integrin aV $\beta 5$ Expression and Inhibited by Edema Toxin (ET)

Integrins $\alpha \mathrm{V} \beta 3$ and $\alpha \mathrm{V} \beta 5$ can act as efferocytic signaling receptors and can depend on soluble cofactor(s) present in the serum such as MFGE8 [17,18]. As efferocytosis by M2(Dex) macrophages was increased in the presence of serum (Figure 4B), we asked whether efferocytosis by M2(Dex) macrophages may be promoted by $\alpha \mathrm{V}$ integrins. We first assessed the expression of $\alpha \mathrm{V} \beta 3$ and $\alpha \mathrm{V} \beta 5$ on the macrophages using flow cytometry. As shown in Figure 5A, M2(Dex) macrophages expressed integrin $\alpha \mathrm{V} \beta 5$ but not integrin $\alpha \mathrm{V} \beta 3$. Efferocytosis by M2(Dex) macrophages in serum-free conditions was significantly enhanced by the opsonization of apoptotic PMN with recombinant MFGE8 (Figure 5B), indicating that efferocytosis by these macrophages depends on $\alpha \mathrm{V} \beta 5$ in addition to MerTK. To determine if ET inhibits efferocytosis under MFGE8/ $\alpha \mathrm{V} \beta 5$-dependent conditions, M2(Dex) macrophages were preincubated with $10 \mathrm{nM} \mathrm{EF}, 10 \mathrm{nM}$ PA, or ET (10 nM PA + $10 \mathrm{nM} \mathrm{EF)}$ or left untreated for $4 \mathrm{~h}$ and then cocultured with human apoptotic PMN opsonized with MFGE8. Efferocytosis after $1 \mathrm{~h}$ of coculture was assessed by flow cytometry. Both serum and MFGE8 enhanced efferocytosis by M2(Dex) macrophages, and this MFGE8-enhanced efferocytosis was inhibited by ET but not by PA or EF alone (Figure 5B). Thus, M2(Dex) macrophages can efferocytose apoptotic PMN through an MFGE8 / $\alpha \mathrm{V} \beta 5$-dependent process that is inhibited by ET. 
A.

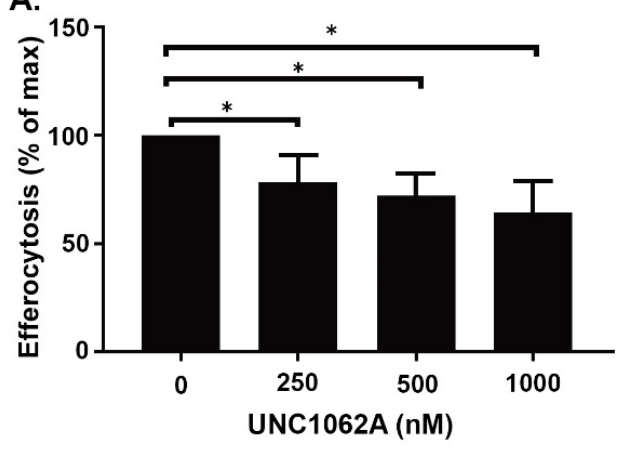

B.

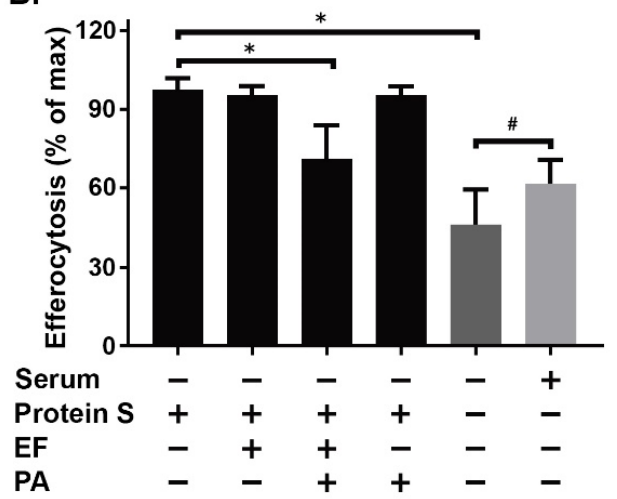

Figure 4. Serum-dependent efferocytosis by M2(Dex) macrophages signals through MerTK and is inhibited by ET. (A) The efferocytosis by M2(Dex) macrophages was preincubated for $1 \mathrm{~h}$ with various concentrations of the selective MerTK inhibitor UNC1062A and then incubated with apoptotic human PMN in the presence of serum for $1 \mathrm{~h}$; (B) The efferocytosis by M2(Dex) macrophages waws preincubated with EF, PA, or ET (PA+EF) or left untreated for $4 \mathrm{~h}$ and then incubated with Protein Sor serum-opsonized apoptotic human PMN for $1 \mathrm{~h}$. The percentages of efferocytic CD206 ${ }^{+}$M2(Dex) macrophages are reported. The data are presented as mean \pm SEM of six individual donors and analyzed using one-way ANOVA followed by Dunnet's multiple comparisons posttest $\left({ }^{*} p<0.05\right)$ or Student's $t$-test $(\# p<0.05)$. The representative flow cytometry gatings for Figure $4 \mathrm{~A}, \mathrm{~B}$ are shown in Figures S2 and S3, respectively.

A.

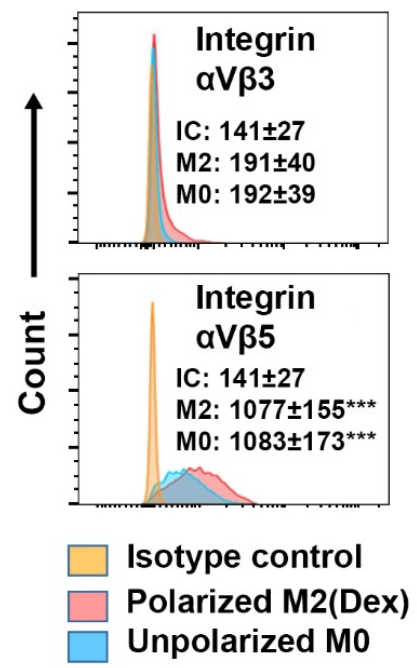

B.

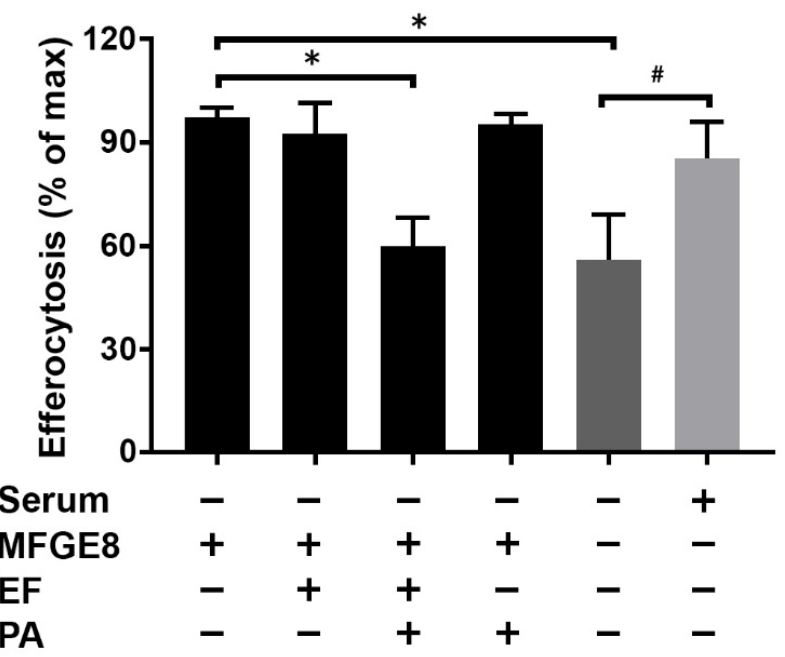

Figure 5. The edema toxin (ET) inhibition of MFGE8-enhanced efferocytosis by human M2(Dex) macrophages is associated with integrin $\alpha \mathrm{V} \beta 5$. (A) The histograms show the expression of cell surface $\alpha \mathrm{V} \beta 5$ but not $\alpha \mathrm{V} \beta 3$ integrin on M2(Dex) macrophages (red, M2) and unpolarized M0 macrophages (blue, M0) compared to M2(Dex) macrophages stained with isotype control antibodies (orange, IC). The mean fluorescence intensities (MFI) \pm SEM of 10 independent donors are indicated. ${ }^{* * *} p<0.001$ by one-way ANOVA with Tukey's multiple comparison posttest compared to IC; (B) M2(Dex) macrophages were preincubated with EF, PA, or ET (PA+EF) or left untreated for $4 \mathrm{~h}$ and then incubated with apoptotic human PMN opsonized with MFGE8 or serum. The percentages of efferocytic CD163 ${ }^{+}$ M2(Dex) macrophages determined by flow cytometry are reported. The data presented are the mean \pm SEM of four individual donors and analyzed using one-way ANOVA followed by Dunnet's multiple comparisons test $\left({ }^{*} p<0.05\right)$ or Student's $t$-test $(\# p<0.05)$. 
2.4. Edema Toxin (ET) Inhibits Rac1 Activation and Alters Cytoskeletal Phosphoprotein Signaling in M2(Dex) Macrophages Induced by Protein S-Opsonized Apoptotic PMN

MerTK and $\alpha \mathrm{V} \beta 5$ signaling lead to Rac1 activation [47], which is essential for efferocytosis [48]. To determine if ET inhibits Rac1 activation in M2(Dex) macrophages downstream of MerTK, M2(Dex) macrophages were preincubated in the presence or absence of ET for $4 \mathrm{~h}$ and then cocultured with Protein S-opsonized apoptotic PMN under serum-free conditions for $15 \mathrm{~min}$. Lysates from each condition were subjected to the pull-down of the active form of Rac. The total and pulled-down Rac1-GTP were quantified by a Western blot. The amount of active Rac1 pulled down from lysates of M2(Dex) macrophages that had been exposed to ET was substantially reduced (Figure 6), indicating that ET inhibits Rac1 activation downstream of the MerTK efferocytic receptor signaling. Similar results were observed in M2(Dex) macrophages stimulated with MFGE8-opsonized apoptotic PMN (Figure S4).

\section{M2(Dex) M2(Dex) M2(Dex) +PMN +PMN+ET}
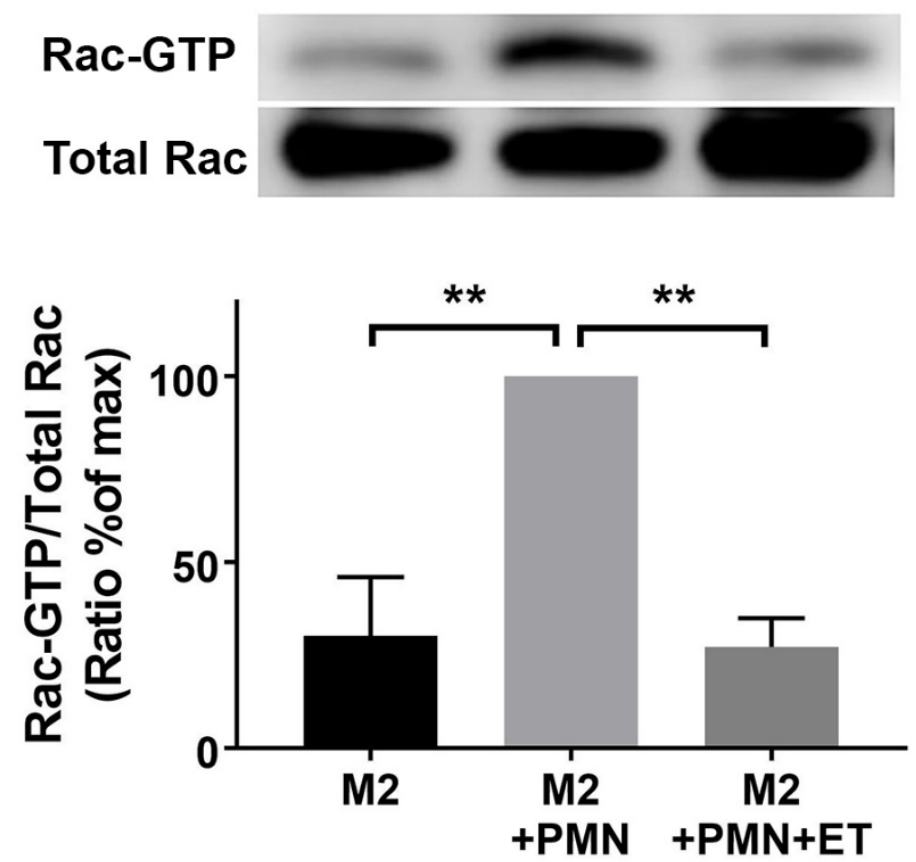

Figure 6. The inhibition of Rac activation by the Edema Toxin: The M2(Dex) macrophages (M2) were preincubated with or without $10 \mathrm{nM}$ ET for $4 \mathrm{~h}$ and then incubated with human apoptotic PMNs that had been opsonized with Protein S for $15 \mathrm{~min}$. The total Rac and Rac-GTP were measured from the lysates by a Western blot. Upper panel: The representative experiment shows the active and total Rac following ECL detection of the Western blot. Lower panel: The quantification of active Rac is expressed as the mean \pm SEM of Rac-GTP/Total Rac ratios expressed as a percentage of the maximum. The data were analyzed by one-way ANOVA with Dunnet's multiple comparison posttest $\left.{ }^{* *} p<0.01\right)$. Treatment with ET inhibited the Rac activation in the presence of Protein S-opsonized apoptotic PMN. The data include results from four independent donors.

To explore whether ET may inhibit other signaling events that impact cytoskeletal reorganization downstream of MerTK, M2(Dex) macrophages were preincubated with ET or left untreated for $4 \mathrm{~h}$ and then cocultured with Protein S-opsonized apoptotic PMN as described above. After 20 min of coculture, the lysates prepared from each condition were biotinylated and assessed for binding to a phospho-proteome array in which solid-phase monoclonal antibodies capture the total or phosphorylated forms of various cytoskeletal-signaling phosphoproteins present in the biotinylated 
lysates. The quantification of the captured proteins, expressed as ratios of phosphorylated to total protein forms, revealed that ET significantly and consistently inhibited the phosphorylation of several phosphoproteins across three independent donors (Table 1). These included CamK1 $\alpha$ (Thr 177), Rac1 (Ser 71), CamK4 (Thr 200), VASP (Ser 157), and MKK3 (Thr 222). In addition, ET showed a tendency to inhibit the phosphorylation of focal adhesion kinase (FAK) at Tyr 925 and VASP at Ser 238 (Table 1). Conversely, ET modestly enhanced the phosphorylation of PIP5K at Ser 307 (Table 1). In terms of the magnitude of inhibition in ET-treated M2(Dex) macrophages, CamK1 $\alpha$, Rac1, CamK4, and VASP were the most affected, with reductions in phosphorylation ranging from approx. 30-50\% (Table 1).

Table 1. Edema Toxin-exposed M2(Dex) macrophages display the reduced phosphorylation of cytoskeletal signaling proteins in response to Protein S-opsonized apoptotic PMN a .

\begin{tabular}{cccccc}
\hline Protein $^{\mathbf{b}}$ & Phospho Site & Mean \pm SEM No ET & Mean \pm SEM ET & $\boldsymbol{p}$-Value & \% Change $^{\mathbf{d}}$ \\
\hline CamK1 $\alpha$ & Thr 177 & $0.897 \pm 0.043$ & $0.533 \pm 0.054$ & 0.006 & $40.6 \downarrow$ \\
Rac1 & Ser 71 & $2.990 \pm 0.251$ & $1.750 \pm 0.056$ & 0.009 & $41.5 \downarrow$ \\
CamK4 & Thr 196/200 & $1.657 \pm 0.102$ & $1.160 \pm 0.017$ & 0.009 & $30.0 \downarrow$ \\
PIP5K & Ser 307 & $0.563 \pm 0.023$ & $0.657 \pm 0.003$ & 0.017 & $16.7 \uparrow$ \\
VASP & Ser 157 & $1.283 \pm 0.166$ & $0.630 \pm 0.135$ & 0.038 & $50.9 \downarrow$ \\
MKK3 & Thr 222 & $0.960 \pm 0.058$ & $0.787 \pm 0.019$ & 0.046 & $18.0 \downarrow$ \\
FAK & Tyr 925 & $1.230 \pm 0.086$ & $0.987 \pm 0.018$ & 0.051 & $19.8 \downarrow$ \\
VASP & Ser 238 & $1.903 \pm 0.133$ & $1.267 \pm 0.200$ & 0.057 & $33.0 \downarrow$ \\
\hline
\end{tabular}

${ }^{a}$ The ratios of the phosphorylated to total forms of the indicated proteins in cell lysates prepared from M2(Dex) macrophages exposed to Protein S-opsonized apoptotic PMN for 20 min are shown. The results compare M2(Dex) macrophages that were (ET) or were not (no ET) pretreated for $4 \mathrm{~h}$ with ET. The data represent the mean \pm SEM of three independent experiments using cell lysates from three different donors; ${ }^{b}$ CamK $1 \alpha=$ calcium calmodulin dependent protein kinase $1 \alpha$, Rac1 = Rac family small GTPase 1, CamK $4=$ calcium calmodulin dependent protein kinase 4, PIP5K = phosphoinositide kinase, FYVE-type zinc finger containing; VASP = vasodilator stimulated phosphoprotein, MKK3 $=$ mitogen-activated protein kinase 3, FAK $=$ focal adhesion kinase; ${ }^{c}$ The $p$-Values determined by the $t$-test comparing the results of three independent experiments using M2(Dex) cells from three different donors; ${ }^{\mathrm{d}} \%$ Change $=\mid[($ Mean No ET - Mean ET $) /$ Mean No ET $] \times 100 \mid$. The arrows indicate an increase or decrease in phosphorylation in the presence of ET.

The phosphorylation of CamK1 $\alpha$ Thr 177 [49], CamK4 Thr 196 [50,51], PIP5K Ser 307 [52], VASP Ser 157 [53], and MKK3 Thr222 [54] are all activating events; thus, the pretreatment of M2(Dex) macrophages with ET results in the down-modulation of the activity of these proteins or their upstream regulators in response to Protein S-opsonized apoptotic PMN. The phosphorylation of FAK Tyr 925 [55,56] and VASP Ser 238 [57] promote cytoskeletal reorganization by altering the molecular associations and/or cellular localization of these proteins. The phosphorylation of Rac1 at Ser 71 promotes filopodia formation in fibroblasts [58]. To assess the effect of ET on actin in macrophages exposed to an efferocytic stimulus, M2(Dex) macrophages were pretreated with ET, co-incubated with Protein S-opsonized apoptotic PMN for $30 \mathrm{~min}$, and then assessed for filamentous actin formation using confocal microscopy. In the absence of ET, CD11 $\mathrm{b}^{+}$macrophages near apoptotic PMN displayed numerous Phalloidin ${ }^{+}$filopodia, whereas similarly positioned macrophages that had been pretreated with ET lacked filopodia (Figure 7). 


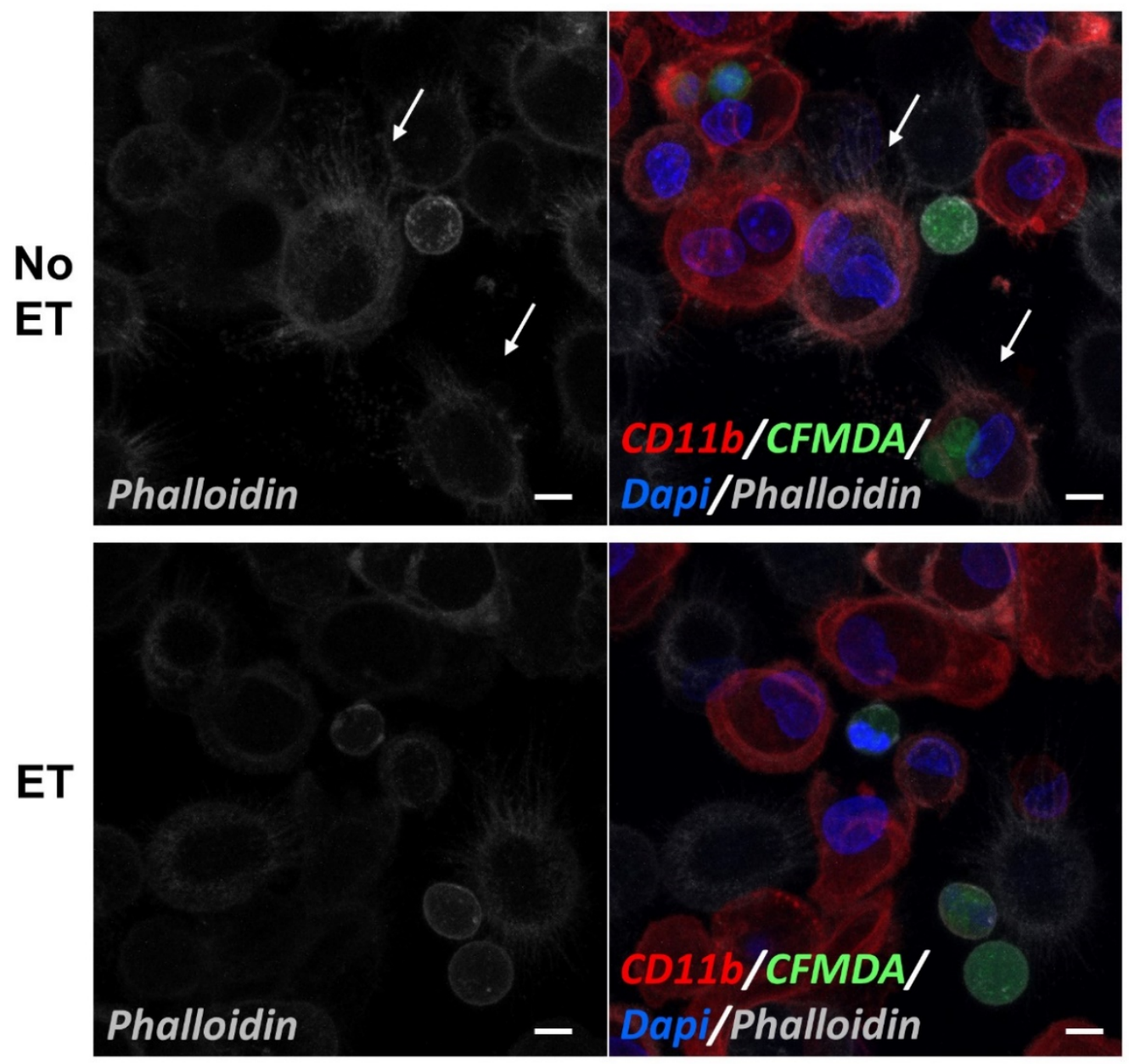

Figure 7. The lack of filopodia in ET-treated CD11b ${ }^{+}$M2(Dex) macrophages in the presence of Protein S-opsonized apoptotic PMN. M2(Dex) macrophages plated in chambered coverglass dishes were preincubated with or without $10 \mathrm{nM}$ ET for $4 \mathrm{~h}$ and then incubated with CFMDA-labeled, Protein S-opsonized apoptotic PMN (green) for $30 \mathrm{~min}$. Following the staining for CD11b with an Alexa647-labeled monoclonal antibody to detect macrophages (red), the fixed cells were stained with Alexa568-labeled Phalloidin to detect filamentous actin (gray) and with DAPI to detect cell nuclei (blue). The z-stack images collected by confocal microscopy are presented as maximal intensity projections to permit the visualization of full cell thicknesses. In the absence of ET exposure (upper panels), Phalloidin ${ }^{+}$filopodia were detected on $\mathrm{CD} 11 \mathrm{~b}^{+}$macrophages near CFMDA-labeled apoptotic cells (white arrows). In contrast, ET-treated $\mathrm{CD}_{11 b^{+}}$macrophages near CFMDA-labeled apoptotic cells (lower panels) lacked obvious filopodia. White bars $=10 \mu \mathrm{m}$.

\section{Discussion}

Edema Toxin is a recognized virulence factor of $B$. anthracis that functions as a highly active calmodulin-dependent adenylate cyclase, raising the concentration of cAMP in cells to supraphysiologic levels [29]. A selective but unidentified role for ET in systemic anthrax infection was recently demonstrated by the reduced survival of macaques infected intravenously with mutant bacilli lacking LF (ET function intact) compared to macaques similarly infected with mutant bacilli lacking PA (neither toxin present) [59]. Although ET was previously shown to inhibit the phagocytosis of B. anthracis bacilli through altered cytoskeletal remodeling [31], defective bacterial clearance did not appear to explain the recently identified selective role of ET in late stage anthrax in the macaque intravenous infection model [59]. Moreover, the specific effects of ET on macrophage cytoskeletal 
remodeling have not been previously defined beyond the roles identified for both Protein Kinase A and exchange protein activated by cAMP (EPAC), which act immediately downstream of cAMP [31].

In the present study, we tested the hypothesis that ET inhibits efferocytosis, a process of apoptotic cell engulfment and clearance that depends on cytoskeletal remodeling requiring Rac1 activation [48] and that has been shown to be inhibited by cAMP [12]. As predicted, we observed that ET inhibited efferocytosis in a dose-dependent manner. The $50 \%$ effective concentration for the inhibition of efferocytosis was calculated to be $0.6 \mathrm{nM}$. Given that circulating LT levels (defined as PA63+LF) in late stage inhalational anthrax in Rhesus macaques can reach 1150-12,100 ng/mL, equivalent to 21-79 $\mathrm{nM}$ [60] and that the ratio of LF:EF in the circulation of lethally infected rabbits is consistently 5:1 at various time points [61], the capacity of ET to inhibit efferocytosis is within the predicted physiologic range of ET encountered during systemic anthrax.

What are the predicted pathologic consequences of impaired efferocytosis during systemic anthrax? Data from lethal human cases of inhalational anthrax and a baboon intravenous bacillus infection model are consistent with sepsis being a factor that contributes to mortality in systemic anthrax [2,3]. A key feature of human sepsis pathology is rapid and widespread lymphocyte apoptosis [5]. Failure to effectively clear apoptotic lymphocytes leads to their secondary necrosis and the subsequent release of nucleosomes/histones and other toxic damage-associated molecular patterns [62]. Circulating nucleosomes/histones cause key features of sepsis pathology, including intra-alveolar hemorrhage, macro- and microvascular thrombosis, and organ dysfunction [9]. Based on these predictions, it was important that we test the impact of ET on efferocytic macrophages having the phenotype of those residing in human secondary lymphoid organs. Efferocytic macrophages in human lymph nodes express CD163 and CD206 [10]. We showed that human monocyte-derived macrophages either expressed or could be induced to express these markers by polarization with IL-4+IL-10+Dex or Dex alone and that ET could inhibit efferocytosis of macrophages with this phenotype.

Understanding the precise mechanisms whereby ET inhibits efferocytosis could lead to new strategies to restore efferocytosis in the setting of late stage anthrax and other forms of acute sepsis. To produce therapeutic effects, however, such strategies should preserve bacterial phagocytosis and/or be used in the context of effective antibiotic therapy. Thus, to further understand how ET subverts intracellular signaling events required for the engulfment of apoptotic cells, efferocytosis assays were conducted under defined conditions. We used conditions that promoted the initiation of efferocytic signaling through MerTK, a relevant efferocytic signaling receptor in the secondary lymphoid organs [10] or through $\alpha \mathrm{V} \beta 5$ integrin that can signal for efferocytosis on its own [18] or in cooperation with MerTK [63]. The expression of MerTK, Tyro 3, and $\alpha \mathrm{V} \beta 5$ (but not Axl or $\alpha \mathrm{V} \beta 3$ ) by M2(Dex) macrophages ensured that signaling initiated by Protein S- or MFGE8-opsonized apoptotic PMN preferentially occurred through these receptors.

An evolutionarily conserved signaling pathway that leads to efferocytosis involves the recruitment of a complex of p130Cas, CrkII, and DOCK-180 proteins to the vicinity of the signaling receptor, resulting in Rac1 activation that leads to cytoskeletal reorganization and engulfment [64]. Experiments conducted in HEK-293T cells showed that MerTK activation leads to the Src-mediated phosphorylation of FAK on Tyr 861, followed by the recruitment of FAK to $\alpha \mathrm{V} \beta 5$, the increased phosphorylation of p130Cas, the increased formation of the p130Cas/CrkII/Dock180 complex, enhanced Rac1 activation, and efferocytosis [63]. The signaling was enhanced synergistically by the presence of $\alpha \mathrm{V} \beta 5$ [63]. Our studies in primary human macrophages revealed that ET could substantially and reproducibly inhibit the activation of Rac1 following the exposure of M2(Dex) macrophages to Protein S-opsonized apoptotic PMN, showing a perturbation of the efferocytic signaling pathway by ET. Although we did not observe a significant inhibition of the phosphorylation of Tyr 861 on FAK across three independent donors, a $49 \%$ and $28 \%$ reduction of phosphorylation of this residue in the presence of ET was observed in two of the three donors (not shown). We did, however, observe a modest but consistent reduction in phosphorylation of FAK Tyr 925. Notably, the phosphorylation of this residue was required for FAK-mediated cell protrusion in mouse embryonic fibroblasts that depended on the 
p130Cas/Dock180/Rac1 signaling pathway [56], suggesting that an interruption of the FAK activation by ET may contribute to its capacity to inhibit efferocytosis. Furthermore, the phosphorylation of FAK at Tyr 925 played a causative role in stimulating the migration of RAW 264.7 mouse macrophages [65], consistent with a role for the inhibition of FAK in the ET-mediated suppression of cell migration [30,35].

The most substantial changes in cytoskeleton signaling protein phosphorylation events downstream of MerTK that were induced by the pre-exposure of macrophages to ET included the reduced phosphorylation of Ser-71 on Rac, as well as the reduced phosphorylation of activating Thr residues of CamKs $1 \alpha$ and 4 and Ser residues of VASP. Though originally reported to be an inhibitory phosphorylation event, Ser-71 phosphorylation on Rac was more recently found to promote filopodia formation in fibroblasts [58]. The predicted effects downstream of Cam kinases [50,51] include altered transcription. Notably, ET has been shown to alter the transcription of macrophages as early as $3 \mathrm{~h}$ posttreatment, and these changes have been proposed to impact cytoskeletal remodeling [31]. VASP has not previously been implicated in efferocytosis, but its localization to the phagocytic cup was shown to be essential for actin cytoskeletal reorganization, the extension of pseudopodia, and phagocytosis by macrophages [66]. In Drosophila macrophages, Ena/VASP stimulates WAVE regulatory complex-mediated actin assembly in the presence of Rac, which is necessary for lamellipodia formation [67], an event also known to be essential for efferocytosis. Consistent with an impact of these phosphorylation events on filopodia formation, we observed a reduced filamentous actin-positive filopodia in ET-treated CD11 $b^{+}$M2(Dex) macrophages exposed to apoptotic PMN (Figure 7). However, this observation requires confirmation in live cell imaging studies to effectively capture actin reorganization events occurring during the process of efferocytosis.

This study establishes the capacity of B. anthracis ET to inhibit macrophage-mediated efferocytosis at doses relevant to systemic infection and further provides novel insight into putative molecular mechanisms.

\section{Materials and Methods}

\subsection{Isolation, Differentiation, and Polarization of Human Monocytes}

The acquisition and use of all human cells in this study was compliant with the Declaration of Helsinki and was reviewed and approved by the Oklahoma Medical Research Foundation Institutional Review Board, ensuring the protection of human subjects. Fresh buffy coats (containing white blood cells and platelets) of healthy blood donors were purchased from the Oklahoma Blood Institute, USA. Mononuclear cells were isolated using Lympholyte-H Cell Separation Media (Cedarlane, Burlington, NC, USA). The monocytes were either purified using an EasySep Human Monocyte Isolation Kit (StemCell Technologies, Cambridge, MA, USA) or isolated as adherent cells according to the following procedure: isolated mononuclear cells were resuspended at $4 \times 10^{6} / \mathrm{mL}$ in Iscove's Modified Dulbecco's Medium (IMDM, Gibco, Grand Island, NY, USA) and adhered to nontreated $100 \mathrm{~mm} \times 20 \mathrm{~mm}$ tissue culture dishes (Corning, Corning, NY, USA) for $1 \mathrm{~h}$ at $37{ }^{\circ} \mathrm{C}$ in $5 \% \mathrm{CO}_{2}$. Nonadherent cells were removed by washing with IMDM. To generate macrophages, monocytes were cultured for 6 or 7 days with $50 \mathrm{ng} / \mathrm{mL}$ M-CSF (Peprotech, Rocky Hill, NJ, USA) in either RPMI 1640 with 10\% FBS, $2 \mathrm{mM}$ glutamine, $100 \mathrm{U}$ pen/strep/mL, $10 \mathrm{mM}$ HEPES buffer, and $1 \mathrm{mM}$ sodium pyruvate (for M2(IL-4+IL-10+Dex) macrophages) or in IMDM containing 10\% FBS and $100 \mathrm{U}$ pen/strep/mL (for M2(Dex) macrophages). On day 7 or 8 , adherent cells were detached using a Trypsin-EDTA solution (Millipore Sigma, St. Louis, MO, USA) and resuspended in a fresh medium with 50 ng/mL M-CSF and 20 ng/mL IL-10 (Peprotech), 20 ng/mL IL-4 (Peprotech), and/or $10 \mathrm{nM}$ dexamethasone (Dex) (Millipore Sigma) at $5 \times 10^{5} /$ well in temperature-sensitive 12 well-plates (Nunc UpCell, Rochester, NY, USA) overnight. 


\subsection{Generation of Early Apoptotic Human Polymorphonuclear Neutrophils (PMN)}

Polymorphonuclear neutrophils (PMN) were isolated from fresh human blood using the EasySep Direct Human Neutrophil Isolation Kit (StemCell Technologies, Cambridge, MA, USA). The isolated PMN were labeled with $10 \mu \mathrm{M}$ eFluor 670 (Cell Proliferation Dye, eBioscience, San Diego, CA, USA), and then, apoptosis was induced by UV irradiation $\left(500 \mathrm{~mJ} / \mathrm{cm}^{2}\right.$ for $2 \mathrm{~min}$ and $\left.41 \mathrm{~s}\right)$ followed by $4 \mathrm{~h}$ of culture at $5 \times 10^{6} / \mathrm{mL}$ in IMDM in the absence of serum at $37^{\circ} \mathrm{C}$ in $5 \% \mathrm{CO}_{2}$ atmosphere. Cultured PMN populations were routinely $>70 \%$ early apoptotic (Annexin $\mathrm{V}^{+} / \mathrm{PI}^{-}$) and $<5 \%$ late apoptotic (Annexin $\mathrm{V}^{+} / \mathrm{PI}^{+}$), as determined by flow cytometry using the Annexin $\mathrm{V}$ Apoptosis Detection Kit FITC (eBioscience; Figure S5). Before the coculture with human M2(Dex) macrophages in various assays, apoptotic PMN were pretreated with either $12 \mu \mathrm{g} / \mathrm{ml}$ Protein S (Enzyme Research Laboratories, South Bend, IN, USA), 12.5 g/mL MFGE8 (R\&D Systems, Minneapolis, MN, USA), or 10\% serum (FBS) for $1 \mathrm{~h}$.

\subsection{Flow Cytometry}

Macrophages were detached from Nunc UpCell tissue culture plastic by incubation in cold PBS on ice for 20-30 min. After washing with ice-cold PBS containing $2 \%$ FBS, the cells ( $5 \times 10^{5} /$ assay) were treated with Human BD Fc block (BD Biosciences, San Jose, CA, USA) for 10 min at room temperature followed by staining with fluorophore-conjugated monoclonal antibodies for $30 \mathrm{~min}$ on ice. The data from washed cells were collected using an LSRII cytometer (BD Biosciences) and analyzed with FlowJo (Treestar, Ashland, OR, USA) software. Efferocytosis receptor antibodies (R\&D Systems) were PE-labeled and included the following specificities and clones: Dtk/Tyro3 (clone 96201), Axl (108724), MerTK (125518), $\alpha$ V 33 (23C6), or $\alpha \mathrm{V} \beta 5$ (P5H9). Other antibodies and clones included PE-Cy7-conjugated antihuman CD80 (BioLegend, San Diego, CA, USA, clone 2D10), PerCp-Cy5.5-conjugated antihuman CD206 (BioLegend, 15-2), APC-Cy7-conjugated antihuman CD163 (BioLegend, GHI/61), and BV-421-conjugated antihuman CD66b (BD Biosciences, G10F5).

\subsection{Efferocytosis Assay}

Efferocytosis was assessed by flow cytometry [68]. Briefly, $5 \times 10^{5} /$ well monocyte-derived human M2(IL-4+IL-10+Dex) macrophages or M2(Dex) macrophages were preincubated with $10 \mathrm{nM}$ recombinant PA (List Biological Laboratories, Campbell, CA, USA), $10 \mathrm{nM}$ recombinant EF (List Biological Laboratories), or various concentrations of PA + EF (ET) for $4 \mathrm{~h}$ at $37{ }^{\circ} \mathrm{C}$ in $5 \%$ $\mathrm{CO}_{2}$ atmosphere. Fluorescently-labeled apoptotic human PMN were preincubated with $10 \%$ serum, Protein S, or MFGE8 for $1 \mathrm{~h}$ unless otherwise noted and then added to the macrophages, resulting in a macrophage:PMN ratio of 1:5. After $1 \mathrm{~h}$ at $37{ }^{\circ} \mathrm{C}$ in $5 \% \mathrm{CO}_{2}$ atmosphere, the percentage macrophages containing intracellular (eFluor $670^{+}$) but not surface-bound (surface $\mathrm{CD}^{2} 6 \mathrm{~b}^{-}$) PMN was assessed by flow cytometry.

\subsection{MerTK Inhibition Efferocytosis Assay}

Human M2(Dex) macrophages $\left(5 \times 10^{5} /\right.$ well) were preincubated with various concentrations $(0-1 \mu \mathrm{M})$ of selective MerTK inhibitor UNC1062A [46] for $1 \mathrm{~h}$ at $37^{\circ} \mathrm{C}$ in $5 \% \mathrm{CO}_{2}$ atmosphere prior to the addition of fluorescently labeled, Protein S-opsonized, human apoptotic PMN. The final macrophage:PMN ratio was 1:5. After $1 \mathrm{~h}$ of coculture, the percentage of macrophages that had engulfed apoptotic PMN was determined by flow cytometry.

\subsection{Rac Pull-Down Assay}

M2(Dex) macrophages were washed four times with PBS and then incubated overnight in IMDM containing $10 \%$ FBS in the absence of M-CSF to reduce M-CSF receptor signaling to a basal state. Rested M2(Dex) macrophages were preincubated in the presence or absence of $10 \mathrm{nM}$ ET for $4 \mathrm{~h}$ at $37{ }^{\circ} \mathrm{C}$ in $5 \% \mathrm{CO}_{2}$ atmosphere, washed four times with PBS, and then cocultured $\left(6 \times 10^{6}\right.$ human 
M2(Dex) macrophages/well) with either Protein S- or MFGE8-opsonized human apoptotic PMN at a 5:1 PMN:M2(Dex) macrophage ratio for 15-20 min. The Rac-GTP and total Rac were measured using a Rac Activation Assay Kit (NewEast Biosciences, King of Prussia, PA, USA), following the protocol described by the manufacturer. The total lysate and Rac-GTP pulled down from lysates were electrophoresed and blotted using the manufacturer's provided anti-Rac polyclonal antibody $(2 \mu \mathrm{g} / \mathrm{mL})$. The immune-reactive bands were visualized using a peroxidase-conjugated goat anti-rabbit immunoglobulin G (IgG) (1:1000 dilution) antibody (WesternSure Goat Anti-Rabbit IgG (H+L), LI-COR) and an ECL Plus Western Blotting Detection System (Azure Biosystems, Dublin, CA, USA). The images were captured using an Azure cSeries C600 (Azure Biosystems) instrument using the imaging workflow for chemiluminescent applications. The quantifications were carried out using Image J software. The ratios of Rac-GTP/Total Rac were expressed as percentages of the maximum ratio within each individual donor.

\subsection{Phosphoprotein Profiling Assay}

M2(Dex) macrophages were washed four times with PBS and then incubated overnight in IMDM containing $10 \%$ FBS in the absence of M-CSF to reduce M-CSF receptor signaling to a basal state. Rested M2(Dex) macrophages were preincubated in the presence or absence of $10 \mathrm{nM}$ ET for $4 \mathrm{~h}$ at $37^{\circ} \mathrm{C}$ in $5 \% \mathrm{CO}_{2}$ atmosphere, washed four times with PBS, and then cocultured $\left(6 \times 10^{6}\right.$ human M2(Dex) macrophages) with Protein S-opsonized human apoptotic PMN at a 5:1 PMN:M2(Dex) macrophage ratio for $20 \mathrm{~min}$. The lysates were biotinylated and used to probe the Cytoskeleton Phospho Antibody Array (Full Moon BioSystems, Sunnyvale, CA, USA) according to the manufacturer's instructions. Biotinylated proteins captured by the arrays were detected using AlexaFluor 555-Streptavidin. The slides were scanned on a GenePix 4000B Microarray scanner at $532 \mathrm{~nm}$, and the images were analyzed with GenePix Pro 7.3.1 software (Molecular Devices, San Jose, CA, USA). The fluorescence signal was obtained by calculating the Foreground (center of signal) to Background (adjacent to signal) Ratio (F/B) of each capture antibody location on the array. The ratios of signals detected by antibodies directed to phosphorylated versus un-phosphorylated proteins were compared in the presence and absence of ET.

\subsection{Confocal Microscopy}

M2(Dex) macrophages were washed four times with PBS, then seeded onto 8-well chambered coverglass plates (Nunc Lab-TekII Chambered Coverglass, Rochester, NY, USA, $2.5 \times 10^{5}$ macrophages/well), and grown overnight in IMDM containing $10 \%$ FBS at $37{ }^{\circ} \mathrm{C}$ in $5 \%$ $\mathrm{CO}_{2}$ atmosphere. The cells were preincubated with or without $10 \mathrm{nM}$ ET for $4 \mathrm{~h}$ and then cocultured with 5-chloromethylfluorescein diacetate (CFMDA, Molecular Probes, Life Technologies, Eugene, OR, USA)-labeled apoptotic PMN that had been opsonized with Protein $S$ at a 5:1 PMN:M2(Dex) macrophage ratio. After $30 \mathrm{~min}$ of co-incubation, the cells were washed three times and blocked with $10 \%$ human $\mathrm{AB}$ serum on ice for $15 \mathrm{~min}$. CD11b was detected by incubating with AlexaFluor647-labeled antihuman CD11b antibody (Clone ICRF44, Southern Biotech, Birmingham, AL, USA) on ice for $1 \mathrm{~h}$. To visualize the actin filaments, the cells were fixed with $2 \%$ para-formaldehyde and then co-stained with Phalloidin-AlexaFluor568 conjugate (Invitrogen, Eugene, OR, USA) at room temperature for 20 min and mounted in Prolong Gold with 4',6-diamidino-2-phenylindole (DAPI) (Life Technologies). The images were captured by optical sectioning on a Zeiss LSM-510 META laser-scanning microscope and cumulatively displayed as maximal intensity projections.

\subsection{Statistical Analyses}

The results are presented as mean \pm SEM, with the number of independent experiments or donors indicated in the figure legends. The results were analyzed by one-way ANOVA followed by a multiple comparisons posttest $(p<0.05)$ or Student's $t$-test $(p<0.05)$ as indicated in the figure legends (GraphPad, San Diego, CA, USA). 
Supplementary Materials: Supplementary materials can be found at http:/ /www.mdpi.com/1422-0067/20/5/ $1167 / \mathrm{s} 1$.

Author Contributions: E.K.D., Z.P., and A.D.F. conceived, designed, and supervised the experiments. E.K.D., C.L., L.P., and Z.P. collected the data. E.K.D., Z.P., S.L., and A.D.F. analyzed the data. X.W. contributed the reagents and materials. J.A.J. contributed the samples. Z.P., A.D.F., E.K.D., and S.K. wrote the manuscript. All authors revised the manuscript.

Funding: This research was funded by NIH U19 grant AI062629 to A.D.F. and J.A.J. and by the University of North Carolina Cancer Research Fund and Federal Funds from the NCI, NIH, under Contract No. HHSN261200800001E to X.W.

Acknowledgments: The authors are grateful to Diana Hamilton and Jacob Bass in the OMRF Flow Cytometry Core Facility for assistance with flow cytometry; to Tim Gross for assistance with the GenePix scanner; to Julie Crane, Ben Fowler, and Justin Willige of the OMRF Imaging Facility for the assistance with the confocal microscopy; to Charmaine Moya for the technical assistance; to Rachel Smith for the assistance with the figures; and to Louise Williamson for the clerical assistance.

Conflicts of Interest: X.W. has filed a patent on UNC1062A and has stock in Meryx, Inc. The remaining authors declare no conflict of interest.

$\begin{array}{ll}\text { Abbreviations } & \\ \text { cAMP } & \text { cyclic adenosine monophosphate } \\ \text { CamK } & \text { Ca }^{2+/} \text { calmodulin-dependent protein kinase } \\ \text { EF } & \text { edema factor } \\ \text { ET } & \text { focal adhesion kinase } \\ \text { FAK } & \text { fetal bovine serum } \\ \text { FBS } & \text { protective antigen } \\ \text { PA } & \text { dexamethasone-polarized M2 macrophages } \\ \text { M2(Dex) } & \text { M2 macrophages polarized with a mixture of IL-4, IL-10, and dexamethasone } \\ \text { M2(IL-4+IL-10+Dex) } & \text { macrophage colony stimulating factor } \\ \text { M-CSF } & \text { Mer proto-oncogene tyrosine kinase } \\ \text { MerTK } & \text { milk fat globulin protein E8 } \\ \text { MFGE8 } & \text { mitogen-activated protein kinase 3 } \\ \text { MKK3 } & \text { phosphoinositide kinase, FYVE-type zinc finger containing } \\ \text { PIP5K } & \text { polymorphonuclear neutrophils } \\ \text { PMN } & \text { vasodilator-stimulated phosphoprotein } \\ \text { VASP } & \end{array}$

\section{References}

1. Dixon, T.C.; Meselson, M.; Guillemin, J.; Hanna, P.C. Anthrax. N. Engl. J. Med. 1999, 341, 815-826. [CrossRef] [PubMed]

2. Coggeshall, K.M.; Lupu, F.; Ballard, J.; Metcalf, J.P.; James, J.A.; Farris, A.D.; Kurosawa, S. The sepsis model: An emerging hypothesis for the lethality of inhalation anthrax. J. Cell. Mol. Med. 2013, 17, 914-920. [CrossRef] [PubMed]

3. Stearns-Kurosawa, D.J.; Lupu, F.; Taylor, F.B., Jr.; Kinasewitz, G.; Kurosawa, S. Sepsis and pathophysiology of anthrax in a nonhuman primate model. Am. J. Pathol. 2006, 169, 433-444. [CrossRef] [PubMed]

4. Hotchkiss, R.S.; Moldawer, L.L.; Opal, S.M.; Reinhart, K.; Turnbull, I.R.; Vincent, J.L. Sepsis and septic shock. Nat. Rev. Dis. Prim. 2016, 2, 16045. [CrossRef] [PubMed]

5. Hotchkiss, R.S.; Nicholson, D.W. Apoptosis and caspases regulate death and inflammation in sepsis. Nat. Rev. 2006, 6, 813-822. [CrossRef] [PubMed]

6. Zeerleder, S.; Stephan, F.; Emonts, M.; de Kleijn, E.D.; Esmon, C.T.; Varadi, K.; Hack, C.E.; Hazelzet, J.A. Circulating nucleosomes and severity of illness in children suffering from meningococcal sepsis treated with protein c. Crit. Care Med. 2012, 40, 3224-3229. [CrossRef] [PubMed]

7. Chen, Q.; Ye, L.; Jin, Y.; Zhang, N.; Lou, T.; Qiu, Z.; Cheng, B.; Fang, X. Circulating nucleosomes as a predictor of sepsis and organ dysfunction in critically ill patients. Int. J. Infect. Dis. 2012, 16, e558-e564. [CrossRef] [PubMed] 
8. Blander, J.M. The many ways tissue phagocytes respond to dying cells. Immunol. Rev. 2017, 277, $158-173$. [CrossRef] [PubMed]

9. Xu, J.; Zhang, X.; Pelayo, R.; Monestier, M.; Ammollo, C.T.; Semeraro, F.; Taylor, F.B.; Esmon, N.L.; Lupu, F.; Esmon, C.T. Extracellular histones are major mediators of death in sepsis. Nat. Med. 2009, 15, 1318-1321. [CrossRef] [PubMed]

10. Baratin, M.; Simon, L.; Jorquera, A.; Ghigo, C.; Dembele, D.; Nowak, J.; Gentek, R.; Wienert, S.; Klauschen, F.; Malissen, B.; et al. T cell zone resident macrophages silently dispose of apoptotic cells in the lymph node. Immunity 2017, 47, 349-362. [CrossRef] [PubMed]

11. McGaha, T.L.; Chen, Y.; Ravishankar, B.; van Rooijen, N.; Karlsson, M.C. Marginal zone macrophages suppress innate and adaptive immunity to apoptotic cells in the spleen. Blood 2011, 117, 5403-5412. [CrossRef] [PubMed]

12. Rossi, A.G.; McCutcheon, J.C.; Roy, N.; Chilvers, E.R.; Haslett, C.; Dransfield, I. Regulation of macrophage phagocytosis of apoptotic cells by camp. J. Immunol. 1998, 160, 3562-3568. [PubMed]

13. Elliott, M.R.; Koster, K.M.; Murphy, P.S. Efferocytosis signaling in the regulation of macrophage inflammatory responses. J. Immunol. 2017, 198, 1387-1394. [CrossRef] [PubMed]

14. Zent, C.S.; Elliott, M.R. Maxed out macs: Physiologic cell clearance as a function of macrophage phagocytic capacity. FEBS J. 2017, 284, 1021-1039. [CrossRef] [PubMed]

15. Greenlee-Wacker, M.C. Clearance of apoptotic neutrophils and resolution of inflammation. Immunol. Rev. 2016, 273, 357-370. [CrossRef] [PubMed]

16. van der Meer, J.H.; van der Poll, T.; van't Veer, C. Tam receptors, gas6, and protein s: Roles in inflammation and hemostasis. Blood 2014, 123, 2460-2469. [CrossRef] [PubMed]

17. Hanayama, R.; Tanaka, M.; Miwa, K.; Shinohara, A.; Iwamatsu, A.; Nagata, S. Identification of a factor that links apoptotic cells to phagocytes. Nature 2002, 417, 182-187. [CrossRef] [PubMed]

18. Akakura, S.; Singh, S.; Spataro, M.; Akakura, R.; Kim, J.I.; Albert, M.L.; Birge, R.B. The opsonin mfg-e8 is a ligand for the alphavbeta5 integrin and triggers dock180-dependent rac1 activation for the phagocytosis of apoptotic cells. Exp. Cell Res. 2004, 292, 403-416. [CrossRef] [PubMed]

19. Jun, J.I.; Kim, K.H.; Lau, L.F. The matricellular protein ccn1 mediates neutrophil efferocytosis in cutaneous wound healing. Nat. Commun. 2015, 6, 7386. [CrossRef] [PubMed]

20. Segura, E.; Valladeau-Guilemond, J.; Donnadieu, M.H.; Sastre-Garau, X.; Soumelis, V.; Amigorena, S. Characterization of resident and migratory dendritic cells in human lymph nodes. J. Exp. Med. 2012, 209, 653-660. [CrossRef] [PubMed]

21. Annane, D.; Bellissant, E.; Bollaert, P.E.; Briegel, J.; Keh, D.; Kupfer, Y. Corticosteroids for treating sepsis. Cochrane Database Syst. Rev. 2015, 12. [CrossRef] [PubMed]

22. Gibbison, B.; Lopez-Lopez, J.A.; Higgins, J.P.; Miller, T.; Angelini, G.D.; Lightman, S.L.; Annane, D. Corticosteroids in septic shock: A systematic review and network meta-analysis. Crit. Care 2017, 21, 78. [CrossRef] [PubMed]

23. McColl, A.; Bournazos, S.; Franz, S.; Perretti, M.; Morgan, B.P.; Haslett, C.; Dransfield, I. Glucocorticoids induce protein s-dependent phagocytosis of apoptotic neutrophils by human macrophages. J. Immunol. 2009, 183, 2167-2175. [CrossRef] [PubMed]

24. Zizzo, G.; Hilliard, B.A.; Monestier, M.; Cohen, P.L. Efficient clearance of early apoptotic cells by human macrophages requires $\mathrm{m} 2 \mathrm{c}$ polarization and mertk induction. J. Immunol. 2012, 189, 3508-3520. [CrossRef] [PubMed]

25. Mock, M.; Fouet, A. Anthrax. Annu. Rev. Microbiol. 2001, 55, 647-671. [CrossRef] [PubMed]

26. Liu, S.; Moayeri, M.; Leppla, S.H. Anthrax lethal and edema toxins in anthrax pathogenesis. Trends Microbiol. 2014, 22, 317-325. [CrossRef] [PubMed]

27. Bradley, K.A.; Mogridge, J.; Mourez, M.; Collier, R.J.; Young, J.A. Identification of the cellular receptor for anthrax toxin. Nature 2001, 414, 225-229. [CrossRef] [PubMed]

28. Scobie, H.M.; Rainey, G.J.; Bradley, K.A.; Young, J.A. Human capillary morphogenesis protein 2 functions as an anthrax toxin receptor. Proc. Natl. Acad. Sci. USA 2003, 100, 5170-5174. [CrossRef] [PubMed]

29. Leppla, S.H. Anthrax toxin edema factor: A bacterial adenylate cyclase that increases cyclic amp concentrations of eukaryotic cells. Proc. Natl. Acad. Sci. USA 1982, 79, 3162-3166. [CrossRef] [PubMed] 
30. Rossi Paccani, S.; Tonello, F.; Patrussi, L.; Capitani, N.; Simonato, M.; Montecucco, C.; Baldari, C.T. Anthrax toxins inhibit immune cell chemotaxis by perturbing chemokine receptor signalling. Cell. Microbiol. 2007, 9, 924-929. [CrossRef] [PubMed]

31. Yeager, L.A.; Chopra, A.K.; Peterson, J.W. Bacillus anthracis edema toxin suppresses human macrophage phagocytosis and cytoskeletal remodeling via the protein kinase a and exchange protein activated by cyclic amp pathways. Infect. Immun. 2009, 77, 2530-2543. [CrossRef] [PubMed]

32. Park, J.M.; Greten, F.R.; Wong, A.; Westrick, R.J.; Arthur, J.S.; Otsu, K.; Hoffmann, A.; Montminy, M.; Karin, M. Signaling pathways and genes that inhibit pathogen-induced macrophage apoptosis—Creb and nf-kappab as key regulators. Immunity 2005, 23, 319-329. [CrossRef] [PubMed]

33. O'Brien, J.; Friedlander, A.; Dreier, T.; Ezzell, J.; Leppla, S. Effects of anthrax toxin components on human neutrophils. Infect. Immun. 1985, 47, 306-310. [PubMed]

34. Wright, G.G.; Mandell, G.L. Anthrax toxin blocks priming of neutrophils by lipopolysaccharide and by muramyl dipeptide. J. Exp. Med. 1986, 164, 1700-1709. [CrossRef] [PubMed]

35. Szarowicz, S.E.; During, R.L.; Li, W.; Quinn, C.P.; Tang, W.J.; Southwick, F.S. Bacillus anthracis edema toxin impairs neutrophil actin-based motility. Infect. Immun. 2009, 77, 2455-2464. [CrossRef] [PubMed]

36. Tournier, J.N.; Quesnel-Hellmann, A.; Mathieu, J.; Montecucco, C.; Tang, W.J.; Mock, M.; Vidal, D.R.; Goossens, P.L. Anthrax edema toxin cooperates with lethal toxin to impair cytokine secretion during infection of dendritic cells. J. Immunol. 2005, 174, 4934-4941. [CrossRef] [PubMed]

37. Cleret-Buhot, A.; Mathieu, J.; Tournier, J.N.; Quesnel-Hellmann, A. Both lethal and edema toxins of bacillus anthracis disrupt the human dendritic cell chemokine network. PLoS ONE 2012, 7, e43266. [CrossRef] [PubMed]

38. Maldonado-Arocho, F.J.; Bradley, K.A. Anthrax edema toxin induces maturation of dendritic cells and enhances chemotaxis towards macrophage inflammatory protein 3beta. Infect. Immun. 2009, 77, 2036-2042. [CrossRef] [PubMed]

39. Comer, J.E.; Chopra, A.K.; Peterson, J.W.; Konig, R. Direct inhibition of t-lymphocyte activation by anthrax toxins in vivo. Infect. Immun. 2005, 73, 8275-8281. [CrossRef] [PubMed]

40. Paccani, S.R.; Tonello, F.; Ghittoni, R.; Natale, M.; Muraro, L.; D’Elios, M.M.; Tang, W.J.; Montecucco, C.; Baldari, C.T. Anthrax toxins suppress t lymphocyte activation by disrupting antigen receptor signaling. J. Exp. Med. 2005, 201, 325-331. [CrossRef] [PubMed]

41. Rossi Paccani, S.; Benagiano, M.; Capitani, N.; Zornetta, I.; Ladant, D.; Montecucco, C.; D’Elios, M.M.; Baldari, C.T. The adenylate cyclase toxins of bacillus anthracis and bordetella pertussis promote th2 cell development by shaping $t$ cell antigen receptor signaling. PLoS Pathog. 2009, 5, e1000325. [CrossRef] [PubMed]

42. Park, S.Y.; Jung, M.Y.; Lee, S.J.; Kang, K.B.; Gratchev, A.; Riabov, V.; Kzhyshkowska, J.; Kim, I.S. Stabilin-1 mediates phosphatidylserine-dependent clearance of cell corpses in alternatively activated macrophages. J. Cell Sci. 2009, 122, 3365-3373. [CrossRef] [PubMed]

43. Ambarus, C.A.; Krausz, S.; van Eijk, M.; Hamann, J.; Radstake, T.R.; Reedquist, K.A.; Tak, P.P.; Baeten, D.L. Systematic validation of specific phenotypic markers for in vitro polarized human macrophages. J. Immunol. Methods 2012, 375, 196-206. [CrossRef] [PubMed]

44. Buechler, C.; Ritter, M.; Orso, E.; Langmann, T.; Klucken, J.; Schmitz, G. Regulation of scavenger receptor cd163 expression in human monocytes and macrophages by pro- and antiinflammatory stimuli. J. Leukoc. Biol. 2000, 67, 97-103. [CrossRef] [PubMed]

45. Jaguin, M.; Houlbert, N.; Fardel, O.; Lecureur, V. Polarization profiles of human m-csf-generated macrophages and comparison of m1-markers in classically activated macrophages from gm-csf and m-csf origin. Cell. Immunol. 2013, 281, 51-61. [CrossRef] [PubMed]

46. Liu, J.; Zhang, W.; Stashko, M.A.; Deryckere, D.; Cummings, C.T.; Hunter, D.; Yang, C.; Jayakody, C.N.; Cheng, N.; Simpson, C.; et al. Unc1062, a new and potent mer inhibitor. Eur. J. Med. Chem. 2013, 65, 83-93. [CrossRef] [PubMed]

47. Wu, Y.M.; Robinson, D.R.; Kung, H.J. Signal pathways in up-regulation of chemokines by tyrosine kinase mer/nyk in prostate cancer cells. Cancer Res. 2004, 64, 7311-7320. [CrossRef] [PubMed]

48. Hoffmann, P.R.; deCathelineau, A.M.; Ogden, C.A.; Leverrier, Y.; Bratton, D.L.; Daleke, D.L.; Ridley, A.J.; Fadok, V.A.; Henson, P.M. Phosphatidylserine (ps) induces ps receptor-mediated macropinocytosis and promotes clearance of apoptotic cells. J. Cell Biol. 2001, 155, 649-659. [CrossRef] [PubMed] 
49. Haribabu, B.; Hook, S.S.; Selbert, M.A.; Goldstein, E.G.; Tomhave, E.D.; Edelman, A.M.; Snyderman, R.; Means, A.R. Human calcium-calmodulin dependent protein kinase i: Cdna cloning, domain structure and activation by phosphorylation at threonine-177 by calcium-calmodulin dependent protein kinase i kinase. EMBO J. 1995, 14, 3679-3686. [CrossRef] [PubMed]

50. Chow, F.A.; Anderson, K.A.; Noeldner, P.K.; Means, A.R. The autonomous activity of calcium/calmodulin-dependent protein kinase iv is required for its role in transcription. J. Biol. Chem. 2005, 280, 20530-20538. [CrossRef] [PubMed]

51. Anderson, K.A.; Noeldner, P.K.; Reece, K.; Wadzinski, B.E.; Means, A.R. Regulation and function of the calcium/calmodulin-dependent protein kinase iv/protein serine/threonine phosphatase 2a signaling complex. J. Biol. Chem. 2004, 279, 31708-31716. [CrossRef] [PubMed]

52. Berwick, D.C.; Dell, G.C.; Welsh, G.I.; Heesom, K.J.; Hers, I.; Fletcher, L.M.; Cooke, F.T.; Tavare, J.M. Protein kinase b phosphorylation of pikfyve regulates the trafficking of glut4 vesicles. J. Cell Sci. 2004, 117, 5985-5993. [CrossRef] [PubMed]

53. Comerford, K.M.; Lawrence, D.W.; Synnestvedt, K.; Levi, B.P.; Colgan, S.P. Role of vasodilator-stimulated phosphoprotein in pka-induced changes in endothelial junctional permeability. FASEB J. 2002, 16, 583-585. [CrossRef] [PubMed]

54. Prickett, T.D.; Brautigan, D.L. Cytokine activation of p38 mitogen-activated protein kinase and apoptosis is opposed by alpha-4 targeting of protein phosphatase 2a for site-specific dephosphorylation of mek3. Mol. Cell. Biol. 2007, 27, 4217-4227. [CrossRef] [PubMed]

55. Katz, B.Z.; Romer, L.; Miyamoto, S.; Volberg, T.; Matsumoto, K.; Cukierman, E.; Geiger, B.; Yamada, K.M. Targeting membrane-localized focal adhesion kinase to focal adhesions: Roles of tyrosine phosphorylation and src family kinases. J. Biol. Chem. 2003, 278, 29115-29120. [CrossRef] [PubMed]

56. Deramaudt, T.B.; Dujardin, D.; Hamadi, A.; Noulet, F.; Kolli, K.; De Mey, J.; Takeda, K.; Ronde, P. Fak phosphorylation at tyr-925 regulates cross-talk between focal adhesion turnover and cell protrusion. Mol. Biol. Cell 2011, 22, 964-975. [CrossRef] [PubMed]

57. Lindsay, S.L.; Ramsey, S.; Aitchison, M.; Renne, T.; Evans, T.J. Modulation of lamellipodial structure and dynamics by no-dependent phosphorylation of vasp ser239. J. Cell Sci. 2007, 120, 3011-3021. [CrossRef] [PubMed]

58. Schwarz, J.; Proff, J.; Havemeier, A.; Ladwein, M.; Rottner, K.; Barlag, B.; Pich, A.; Tatge, H.; Just, I.; Gerhard, R. Serine-71 phosphorylation of rac1 modulates downstream signaling. PLoS ONE 2012, 7, e44358. [CrossRef] [PubMed]

59. Hutt, J.A.; Lovchik, J.A.; Drysdale, M.; Sherwood, R.L.; Brasel, T.; Lipscomb, M.F.; Lyons, C.R. Lethal factor, but not edema factor, is required to cause fatal anthrax in cynomolgus macaques after pulmonary spore challenge. Am. J. Pathol. 2014, 184, 3205-3216. [CrossRef] [PubMed]

60. Boyer, A.E.; Gallegos-Candela, M.; Quinn, C.P.; Woolfitt, A.R.; Brumlow, J.O.; Isbell, K.; Hoffmaster, A.R.; Lins, R.C.; Barr, J.R. High-sensitivity maldi-tof ms quantification of anthrax lethal toxin for diagnostics and evaluation of medical countermeasures. Anal. Bioanal. Chem. 2015, 407, 2847-2858. [CrossRef] [PubMed]

61. Molin, F.D.; Fasanella, A.; Simonato, M.; Garofolo, G.; Montecucco, C.; Tonello, F. Ratio of lethal and edema factors in rabbit systemic anthrax. Toxicon 2008, 52, 824-828. [CrossRef] [PubMed]

62. Sachet, M.; Liang, Y.Y.; Oehler, R. The immune response to secondary necrotic cells. Apoptosis 2017, 22, 1189-1204. [CrossRef] [PubMed]

63. Wu, Y.; Singh, S.; Georgescu, M.M.; Birge, R.B. A role for mer tyrosine kinase in alphavbeta5 integrin-mediated phagocytosis of apoptotic cells. J. Cell Sci. 2005, 118, 539-553. [CrossRef] [PubMed]

64. Albert, M.L.; Kim, J.I.; Birge, R.B. Alphavbeta5 integrin recruits the crkii-dock180-rac1 complex for phagocytosis of apoptotic cells. Nat. Cell Biol. 2000, 2, 899-905. [CrossRef] [PubMed]

65. Thapa, B.; Koo, B.H.; Kim, Y.H.; Kwon, H.J.; Kim, D.S. Plasminogen activator inhibitor-1 regulates infiltration of macrophages into melanoma via phosphorylation of fak-tyr(9)(2)(5). Biochem. Biophys. Res. Commun. 2014, 450, 1696-1701. [CrossRef] [PubMed]

66. Coppolino, M.G.; Krause, M.; Hagendorff, P.; Monner, D.A.; Trimble, W.; Grinstein, S.; Wehland, J.; Sechi, A.S. Evidence for a molecular complex consisting of fyb/slap, slp-76, nck, vasp and wasp that links the actin cytoskeleton to fcgamma receptor signalling during phagocytosis. J. Cell Sci. 2001, 114, 4307-4318. [PubMed] 
67. Chen, X.J.; Squarr, A.J.; Stephan, R.; Chen, B.; Higgins, T.E.; Barry, D.J.; Martin, M.C.; Rosen, M.K.; Bogdan, S.; Way, M. Ena/vasp proteins cooperate with the wave complex to regulate the actin cytoskeleton. Dev. Cell. 2014, 30, 569-584. [CrossRef] [PubMed]

68. Jersmann, H.P.; Ross, K.A.; Vivers, S.; Brown, S.B.; Haslett, C.; Dransfield, I. Phagocytosis of apoptotic cells by human macrophages: Analysis by multiparameter flow cytometry. Cytom. Part A 2003, 51, 7-15. [CrossRef] [PubMed] 